УДК 551.799:502.6(261.24)

РАСПРЕДЕЛЕНИЕ И ГРАНУЛОМЕТРИЧЕСКИЙ СОСТАВ ДОННЫХ ПЕСЧАНЫХ ОТЛОЖЕНИЙ КАЛИНИНГРАДСКОГО ЗАЛИВА

\author{
Чечко В.А., Бабаков А.Н., Топчая В.Ю. \\ ФГБУН «Институт океанологии им. П.П. Шириова» Российской академии наук, Москва, \\ e-mail: che-chko@mail.ru
}

\begin{abstract}
Донные отложения являются интегрирующим показателем условий седиментации и окружающей среды. Поэтому использование их литологических характеристик для оценки состояния водных экосистем и степени антропогенной нагрузки на них является вполне обоснованным. Особенно важными являются сведения о гранулометрическом составе осадков, т.е. о процентном содержании той или иной фракции. Именно от размерного состава осадков зависит их способность накапливать различные поллютанты. Поэтому особое значение в водоемах с интенсивным хозяйственным использованием имеет изучение песчаных отложений, как наименее подверженных такому накоплению. Они являются необходимым и наиболее доступным строительным материалом, удобными пастбищами и нерестилищами для рыб, участки их распространения наименее загрязнены и поэтому привлекательны как рекреационные объекты. В работе представлены результаты изучения 39 проб донных песчаных отложений, отобранных в восточной части Калининградского залива. На основании гранулометрического анализа составлена схема распределения песков. Показано, что они распространены вдоль берегов залива до глубин 2,5-3,0 м. В основном они представлены средними и мелкими песками. Наиболее распространенными песками являются мелкие (0,250-0,125 мм) пески. Это преимущественно современные, хорошо отмытые полевошпатово-кварцевые образования светло-серых оттенков. Содержание преобладающей фракции в их составе колеблется в диапазоне от 36 до $71 \%$, они также характеризуются хорошей сортированностью (Sо в среднем составляет 1,6 ) и отсутствием илистых и глинистых частиц. На поверхности дна в районе распространения средних песков повсеместно развита тонкая окисленная пленка, свидетельствующая о хорошей аэрации придонного слоя. Содержание СаСо составляет в песках в среднем около $1 \%$, а органического углерода около $0,5 \%$. Основным минералом песчаных отложений является кварц (75-85\%), а второстепенными компонентами - калиевые полевые шпаты, глауконит, гранаты, обломки пород.
\end{abstract}

Ключевые слова: Калининградский залив, донные отложения, гранулометрический состав

\title{
DISTRIBUTION AND GRAIN SIZE COMPOSITION OF BOTTOM SANDY SEDIMENTS OF THE KALININGRAD BAY
}

\author{
Chechko V.A., Babakov A.N., Topchaya V.Yu. \\ P.P. Shirshov Institute of Oceanology Russian Academy of Sceinces, Moscow, e-mail: che-chko@mail.ru
}

Bottom sediments are an integrating indicator of sedimentation and environmental conditions. Therefore, the use of their lithological characteristics to assess the state of aquatic ecosystems and the degree of anthropogenic load on them is quite reasonable. Particularly important are the data on the granulometric composition of precipitation, i.e., on the percentage of a particular fraction. Precisely on the size composition of precipitation depends on their ability to accumulate various pollutants. Therefore, the study of sand deposits, as the least susceptible to such accumulation, is of particular importance in reservoirs with intensive economic use. They are the necessary and most affordable building material, convenient pastures and spawning grounds for fish, their distribution areas are the least polluted and, therefore, attractive as recreational facilities. The paper presents the results of the study of 39 samples of bottom sand deposits selected in the Eastern part of the Kaliningrad Bay. On the basis of the grain size analysis the scheme of distribution of sands is made. It is shown that they are distributed along the shores of the Bay to depths of 2.5-3.0 m. they are mainly represented by medium and fine sands. The most common sands are small $(0.250-0.125 \mathrm{~mm})$ sands. These are predominantly modern, well-washed feldspar-quartz formations of light gray shades. The content of the predominant fraction in their composition ranges from 36 to $71 \%$, they are also characterized by good sorting (So on average 1.6) and the absence of silty and clay particles. A thin oxidized film is everywhere developed on the bottom surface in the area of medium sand distribution, indicating a good aeration of the bottom layer. The content of $\mathrm{CaCO} 3$ in the sands averages about $1 \%$, and organic carbon about $0.5 \%$. The main mineral of sand deposits is quartz (75-85\%), and minor components are potassium feldspar, glauconite, pomegranates, rock fragments.

Keywords: Kaliningrad Bay, bottom sediments, grain size composition

Водные объекты с интенсивной хозяйственной деятельностью, расположенные в береговой зоне, динамично развивающейся и находящейся под сильным антропогенным прессом, требуют повышенного внимания ученых и исследователей. К таким объектам можно отнести и Вислинский залив, находящийся в юго-восточной ча- сти Балтийского моря. Его северо-восточная половина находится под юрисдикцией России и называется Калининградским заливом (рис. 1). Это достаточно специфический природный водный объект, в котором происходит смешение и трансформация речных и морских вод, а также взвешенного осадочного материала под влиянием сгон- 
но-нагонных явлений [1]. Основная доля речного стока приходится на р. Преголю, а морские воды поникают в залив через Балтийский пролив.

Антропогенная нагрузка на экосистему Калининградского залива обусловлена рядом факторов. Прибрежная территория залива характеризуется высокой плотностью населения, здесь сосредоточено около $56 \%$ жителей Калининградской области. По акватории залива проложен глубоководный морской канал с круглогодичным функционированием и регулярным проведением дноуглубительных работ. На юго-восточном побережье расположен карьер по добыче песчано-гравийных смесей. В заливе ведется добыча рыбы, что сопряжено с активной деятельностью рыболовецких судов. Все это требует комплексных, междисциплинарных исследований всех компонент экосистемы залива.

Отдельный интерес при этом представляют донные отложения, являющиеся интегрирующим показателем условий седиментации и окружающей среды. Донные отложения - важнейший компонент экосистемы, субстанция, в которой происходит обмен веществом и энергией. Их физикохимический состав во многом определяет направление и скорость процессов как вторичного загрязнения, так и самоочищения. Литологические характеристики донных осадков могут быть использованы при оценке состояния водных экосистем и степени антропогенной нагрузки на них [2-4]. Особенно важными являются сведения о гранулометрическом составе осадков, т.е. о процентном содержании той или иной фракции. Именно от размерного состава осадков зависит их способность накапливать различные поллютанты. Потенциальными накопителями загрязняющих веществ являются осадки с большой долей в их составе тонких, илистых частиц. Естественно, что вторичное загрязнение водной среды от песков будет значительно меньше, чем от илистых отложений [5].

Поэтому особое значение в водоемах с интенсивным хозяйственным использованием имеет изучение песчаных отложений, выяснение их размерных и вещественных характеристик, уточнение ареалов распространения. Именно песчаные отложения являются необходимым и наиболее доступным строительным материалом, удобными пастбищами и нерестилищами для рыб, участки их распространения наименее загрязнены и поэтому привлекательны с точки зрения их использования как рекреационных объектов.

Цель данной работы: на основе литературных данных и результатов, полученных в ходе полевых экспедиционных исследований определить ареалы распространения донных песчаных отложений в Калининградском заливе и выявить особенности их гранулометрического состава.

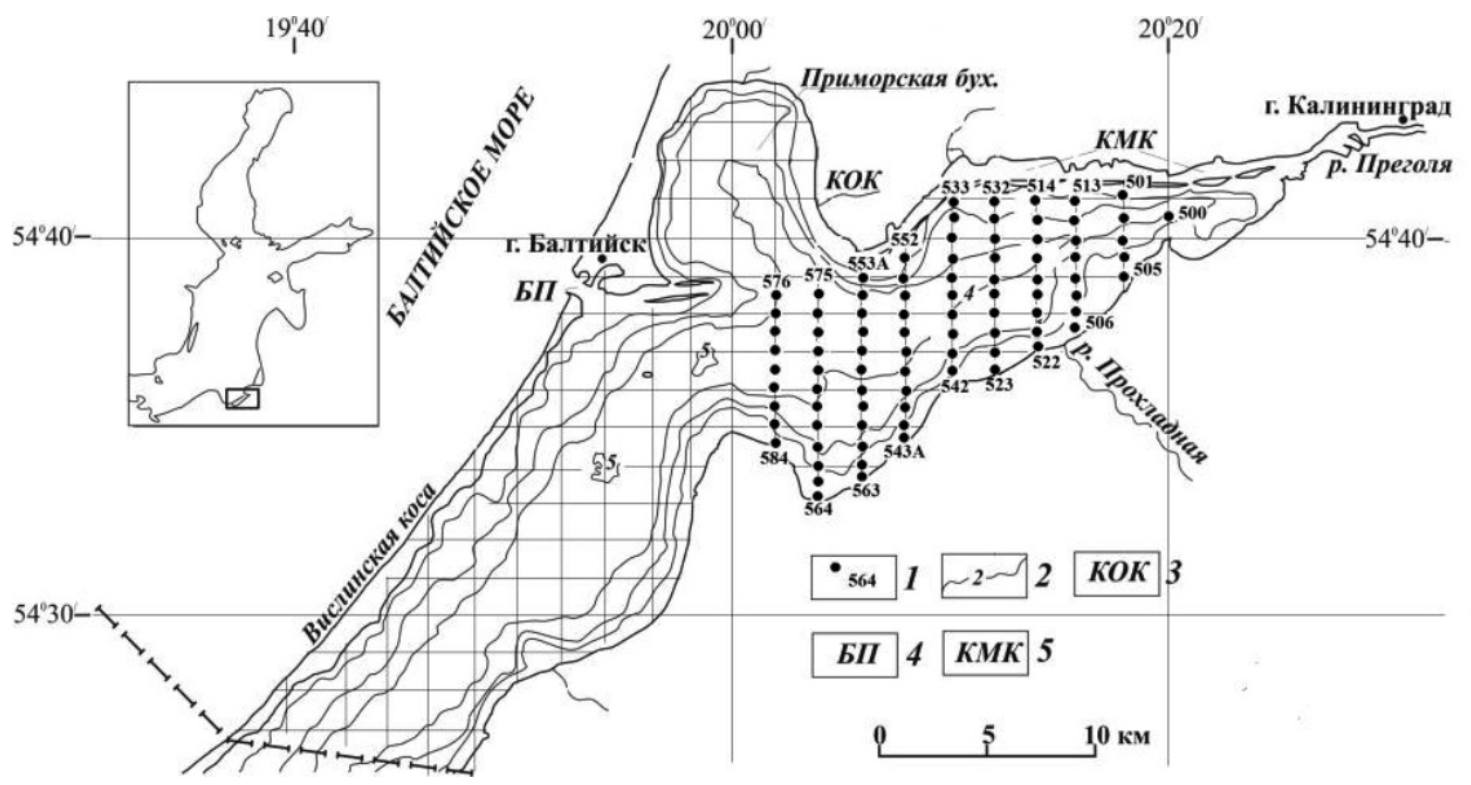

Рис. 1. Карта-схема расположения станций в акватории Калининградского залива: 1 - станция и ее номер, 2 - изобаты, м., 3 - Калининградский отводной канал, 4 - Балтийский пролив, 5 - Калининградский морской канал 


\section{Материалы и методы исследования}

Пробы донных отложений были отобраны во время литологической съёмки Калининградского залива в 2019 г. на 87 станциях (рис. 1). Они отбирались с помощью пробоотборника Петерсена из верхнего (0-7 см) слоя осадков. Первичная обработка полученных образцов донных осадков осуществлялась по методике, используемой сотрудниками Института океанологии РАН в морских геологических экспедициях [6]. В лабораторных условиях полученные образцы донных осадков были подвергнуты гранулометрическому анализу ситовым (фракции $>0,04$ мм) и водно-механическим (фракции <0,04 мм) методами [7]. На основании результатов гранулометрического анализа были выделены слледующие размеры фракций: $>4,0 ; 4,0-2,0 ; 2,0-1,0 ; 1,0-$ 0,$5 ; 0,5-0,250 ; 0,250-0,125 ; 0,125-0,063$; $0,063-0,04 ; 0,04-0,016 ; 0,016-0,008$; $0,008-0,004 ; 0,004-0,002 ; 0,002-0,001$.

В соответствии с классификацией [8], пески были определены как фракция 2,0 0,063 мм, включающая пять подклассов: очень крупный песок $(2,0-1,0$ мм $)$, крупный $(1,0-0,5$ мм), средний $(0,5-0,25$ мм), мелкий $(0,250-0,125 \mathrm{Mм})$ и очень мелкий $(0,125-$ 0,063 мм) песок. Установление таких размеров за нижний и верхний пределы песчаных частиц основано на исследовании скоростей осаждения частиц разной крупности в воде, способов переноса и их физических свойств, изученных многими учеными.

На основании результатов гранулометрического анализа графическим способом были рассчитаны медианный диаметр частиц (Md) и коэффициент сортированности (So). Согласно [9] в хорошо сортированных песках So $<2$, в средне сортированных So $=2-3$, в плохо сортированных So $>3$.

Используя трехкомпонентную (песок ил - глина) диаграмму Ф. Шепарда [10], учитывая медианный диаметр частиц, размер преобладающей фракции и ее процентное содержании в пробе, дополнительно были выделены литологические типы осадков песок алевритовый и алеврит песчанистый.

\section{Результаты исследования и их обсуждение}

Наиболее полное описание донных осадков Калининградского залива, основанное на материалах, собранных в 1992-1996 гг., дано в работе [11]. В ней, однако, с целью получения общей картины распределения осадков, авторы прибегли к серьезной ге- нерализации в связи с несколько хаотичным расположением станций отбора проб, обусловленным решением ряда междисциплинарных задач, а также с достаточно растянутым во времени (около 5 лет) периодом сбора материала. К тому же типизация осадков была выполнена по десятичной системе, имеющей определенные недостатки, а песчаным отложениям в данной работе было уделено явно подчиненное внимание.

На поверхности дна Калининградского залива развиты современные донные осадки, которые являются продуктом осадкообразования, происходящего в настоящее время. В самом общем виде для распределения донных осадков характерно чередование участков песков, песчанистых отложений различной степени заиления и илов различной дисперсности от берегов в сторону центральной, наиболее углубленной части залива. В генетическом отношении в Калининградском заливе на поверхности дна распространены терригенные осадочные образования с большим спектром размерности - валуны, гравий, галька, разнозернистые пески, алевриты и алевритово-пелитовые илы. Минимальными (около $1 \%$ ) содержаниями карбоната кальция (CaCo3) отличаются песчаные отложения, максимальными (6-7\%) - мелкоалевритовые илы. Подобная тенденция выявлена и при распределении органического углерода $\left(\mathrm{C}_{\text {орг }}\right)$ в осадках. Минимальные $(0,5 \%)$ содержания $\mathrm{C}_{\text {орг }}$ характерны для хорошо сортированных песков, максимальными значениями органического углерода (>10\%) характеризуются алевритово-пелитовые илы, распространенные в юго-западной части Калининградского залива $[12,13]$. Характерная особенность песчаных отложений наличие на их поверхности тонкой окисленной пленки, свидетельствующей о хорошем перемешивании вод и отсутствии застойных явлений в местах их развития.

Характер распространения песчаного материала показывает, что максимальные его концентрации сосредоточены в узкой прибрежной полосе, что обусловлено, повидимому, высокой подвижностью всей водной толщи на мелководье и, как следствием, взмучиванием донных отложений с последующим выносом тонких частиц в более углубленные места (рис. 2). Полоса распространения песков ограничивается глубинами 0,8-3,0 м. Достаточно большой диапазон глубин залегания песчаных отложений объясняется расположением источников поступления песка, конфигурацией 
беговой линии и в целом гидродинамическими особенностями конкретных участков залива. У южного побережья напротив устья р. Прохладной полоса песков заметно расширяется. Это можно объяснить особенностью геологического строения прилегающей к заливу территории, влиянием речного стока, а также открытостью акватории для преобладающих в регионе ветров западных и северо-западных румбов, вызывающих волнение и, как следствие, усиление процессов механической дифференциации осадочного материала.

Гранулометрический спектр песков (таблица) и их пространственное распределение варьируют довольно в широких пределах. Исключение составляют очень крупные $(2,0-1,0$ мм) и крупные $(1,0-$ 0,5 мм) пески. Как показали проведенные исследования, на акватории восточной части Калининградского залива они имеют исключительно локальное развитие.

Небольшое пятно крупного песчаного материала выявлено напротив устья р. Прохладной на глубинах 2,0-3,0 м.

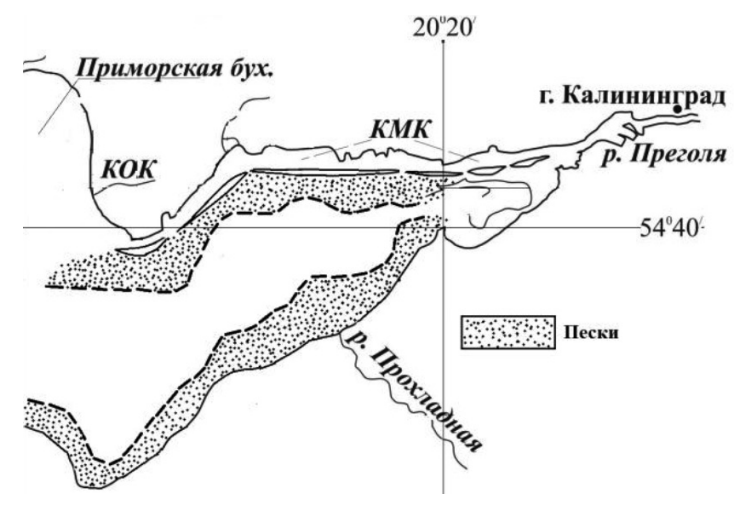

Рис. 2. Схема распределения донных песчаных отложений в восточной части Калининградского залива

По сравнению с крупными песками, среднезернистые пески $(\mathrm{Md}=0,25-0,46$ мм занимают достаточно существенные площади дна залива, особенно в юго-восточной прибрежной мелководной зоне. На этом участке распространены хорошо сортированные среднезернистые пески, генетически связанные с зандровыми полями прилегающей суши. Узкая полоса среднезернистых песков протягивается вдоль дамб, отделяющих морской канал от акватории залива. Среднезернистые пески характеризуются серыми, светло-серыми оттенками и по своим физическим свойствам близки к мелкозернистым пескам. Они также хорошо отмыты, од- нородны и характеризуются очень хорошей сортированностью (So в среднем составляет 1,47). Фракция 0,5 - 0,25 мм в гранулометрическом составе является преобладающей, но ее содержание не очень высоко (36-60\%). Основной примесью являются крупные песчаные частицы, доля которых может достигать 20-27\%. Характерная особенность их состава - практически полное отсутствие более тонких компонентов (таблица).

На поверхности дна в районе распространения средних песков повсеместно развита тонкая окисленная пленка, свидетельствующая о хорошей аэрации придонного слоя. На всех станциях был обнаружен новый вселенец - Североамериканский солоноватоводный двустворчатый моллюск Rangia cuneata, впервые зарегистрированный в Калининградском заливе в сентябре 2010 г. [14]. В составе средних песков содержится, как правило, значительная доля крупных обломков створок моллюсков и раковинного детрита. Основным минералом средних песков является кварц (75-85\%), а второстепенными компонентами - калиевые полевые шпаты, глауконит, гранаты, обломки пород.

Наиболее распространенным песками являются мелкие $(0,250-0,125$ мм) пески. Это преимущественно современные, хорошо отмытые полевошпатово-кварцевые образования светло-серых оттенков. Содержание преобладающей фракции в их составе колеблется в диапазоне от 36 до $71 \%$, они также характеризуются хорошей сортированностью (So в среднем составляет 1,6) и отсутствием илистых и глинистых частиц (таблица). Основной примесью в составе мелкозернистых песков выступают частицы очень мелких и средних песков (содержание последних в некоторых пробах достигает $40 \%$ ), а также раковинный детрит. На мелких песках, как и на средних, также повсеместно развита окисленная пленка и обитает моллюск Rangia cuneata.

Очень мелкие пески не имеют широкого распространения, они встречаются в виде небольших по площади пятен вдоль северного побережья залива. Глубина их залегания варьирует в диапазоне глубин 2,5-3,0 м, т.е., как наиболее подвижные частицы в составе песков, они выносятся в углубленные участки с мелководья в результате механической дифференциации. Они характеризуются высоким содержанием фракции $0,125-0,063$ мм, достигающей $80 \%$, и очень хорошей сортированностью (So в среднем составляет 1,4$)$. Основной примесью в составе очень мелких песков являются мел- 
кие пески (20-23\%), а содержание илистых и глинистых частиц, по сравнению с другими песчаными фракциями, достаточно велико и достигает 7-12\%.

В сыром виде это слабоуплотненные осадки серых оттенков, которые при высыхании легко рассыпаются, так как содержат мало илистых частиц. Очень мелкие пески имеют полевошпатово-кварцевый и глауконитово-кварцевый состав, особенностью их является обогащенность тяжелыми ми- нералами - ильменитом, амфиболами, эпидотом, гранатом, цирконом. В составе очень мелких песков встречаются в большом количестве целые створки раковин моллюсков, их осколки, раковинный детрит, а также живые двустворчатые моллюски Rangia cuneata. Пески алевритовые (содержание илистых частиц более $30 \%$ ) имеют ограниченное распространение, они были выявлены на ст. 565 и 583 на глубинах 2,4 и 3,2 м у южного побережья залива.

Гранулометрический состав донных песчаных отложений восточной части Калининградского залива

\begin{tabular}{|c|c|c|c|c|c|c|c|c|c|c|c|c|c|}
\hline \multirow{2}{*}{$\begin{array}{c}\text { Стан- } \\
\text { ция, } \\
\text { № }\end{array}$} & \multirow{2}{*}{$\begin{array}{c}\text { Глууб., } \\
\text { м }\end{array}$} & \multicolumn{9}{|c|}{ Содержание фракций (мм),\% } & \multirow[t]{2}{*}{ Md } & \multirow[t]{2}{*}{$\mathrm{S}_{0}$} & \multirow{2}{*}{$\begin{array}{c}\text { Типы } \\
\text { осадков }\end{array}$} \\
\hline & & $>4,0$ & $4-2$ & $2-1$ & $1-0,5$ & $0,5-0,25$ & $0,25-0,125$ & $0,125-0,063$ & $0,063-0,04$ & $<0,04$ & & & \\
\hline 501 & 2,4 & 0,0 & 0,0 & 0,0 & 0,0 & 6,5 & 58,5 & 26,0 & 7,5 & 1,2 & 0,15 & 1,4 & М.П. \\
\hline 502 & 2,8 & 1,0 & 2,0 & 12,6 & 27,3 & 36,4 & 19,6 & 0,6 & 0,1 & 0,0 & 0,46 & 1,7 & С.П. \\
\hline 503 & 1,9 & 1,8 & 1,5 & 3,5 & 27,5 & 64,0 & 1,2 & 0,2 & 0,0 & 0,0 & 0,42 & 1,2 & С.П. \\
\hline 504 & 2,5 & 1,5 & 2,0 & 4,2 & 24,5 & 41,5 & 22,0 & 9,2 & 0,1 & 0,0 & 0,33 & 1,7 & С.П. \\
\hline 505 & 1,0 & 0,0 & 1,0 & 9,2 & 18,0 & 40,0 & 23,4 & 8,4 & 0,0 & 0,0 & 0,33 & 1,8 & $\mathrm{C}, \Pi$ \\
\hline 506 & 1,0 & 5,0 & 3,5 & 8,0 & 20,5 & 29,0 & 15,0 & 18,5 & 0,5 & 0,0 & 0,36 & 2,2 & С.П. \\
\hline 507 & 1,9 & 0,0 & 2,4 & 2,8 & 5,6 & 26,8 & 39,5 & 22,6 & 0,1 & 0,0 & 0,19 & 1,6 & М.П. \\
\hline 512 & 2,5 & 0,0 & 0,0 & 0,2 & 3,0 & 43,2 & 52,5 & 0,5 & 0,5 & 0,0 & 0,24 & 1,4 & М.П. \\
\hline 513 & 1,6 & 0,5 & 2,2 & 1,6 & 5,6 & 53,1 & 36,6 & 0,1 & 0,0 & 0,0 & 0,28 & 1,5 & С.П. \\
\hline 514 & 0,4 & 1,7 & 2,0 & 2,5 & 28,0 & 60,0 & 4,0 & 1,0 & 0,1 & 0,0 & 0,43 & 1,4 & С.П. \\
\hline 519 & 3,0 & 0,0 & 0,5 & 8,5 & 78,5 & 11,0 & 0,5 & 0,5 & 0,2 & 0,0 & 0,69 & 1,3 & К.П. \\
\hline 521 & 2,4 & 0,0 & 1,8 & 39,0 & 30,4 & 2,2 & 8,0 & 17,3 & 1,0 & 0,0 & 0,8 & 2,4 & К.П. \\
\hline 522 & 1,5 & 0,0 & 0,0 & 0,1 & 4,8 & 32,3 & 37,2 & 21,7 & 0,1 & 0,0 & 0,2 & 1,6 & М.П. \\
\hline 523 & 1,0 & 0,0 & 0,0 & 0,2 & 1,2 & 56,2 & 33,0 & 9,4 & 0,2 & 0,0 & 0,27 & 1,5 & С.П. \\
\hline 524 & 1,5 & 0,0 & 0,0 & 0,0 & 2,5 & 46,5 & 50,6 & 0,2 & 0,0 & 0,0 & 0,25 & 1,7 & М.П. \\
\hline 525 & 1,7 & 0,0 & 0,0 & 0,0 & 1,0 & 45,5 & 52,6 & 0,2 & 0,0 & 0,0 & 0,25 & 1,6 & М.П. \\
\hline 531 & 3,0 & 0,0 & 0,0 & 6,0 & 7,5 & 12,5 & 13,0 & 34,5 & 25,5 & 0,8 & 0,1 & 2,2 & О.М.П. \\
\hline 532 & 2,8 & 0,0 & 0,0 & 4,0 & 7,0 & 13,0 & 20,0 & 44,5 & 11,5 & 0,0 & 0,12 & 1,8 & О.М.П. \\
\hline 533 & 1,0 & 0,0 & 0,5 & 0,5 & 4,2 & 37,0 & 49,5 & 7,5 & 0,5 & 0,0 & 0,22 & 1,5 & М.П. \\
\hline $533 a$ & 2,7 & 0,0 & 0,0 & 1,0 & 10,5 & 27,0 & 44,0 & 15,5 & 2,0 & 0,0 & 0,2 & 1,6 & М.П. \\
\hline 541 & 1,5 & 0,0 & 0,0 & 0,3 & 3,5 & 37,2 & 58,0 & 0,3 & 0,0 & 0,0 & 0,19 & 1,6 & М.П. \\
\hline 542 & 1,2 & 0,0 & 0,0 & 1,0 & 4,5 & 29,2 & 37,4 & 27,0 & 0,8 & 0,0 & 0,18 & 1,6 & М.П. \\
\hline $543 a$ & 0,9 & 0,0 & 0,0 & 0,0 & 0,3 & 27,0 & 71,2 & 1,2 & 0,0 & 0,0 & 0,17 & 1,3 & М.П. \\
\hline 543 & 1,0 & 0,0 & 0,0 & 0,0 & 0,2 & 28,0 & 70,0 & 1,0 & 0,0 & 0,0 & 0,19 & 1,3 & М.П. \\
\hline 544 & 3,0 & 0,0 & 0,0 & 0,0 & 0,2 & 12,0 & 23,4 & 57,0 & 7,3 & 0,2 & 0,11 & 1,5 & О,М.П. \\
\hline 550 & 3,2 & 0,0 & 0,0 & 0,1 & 1,0 & 2,6 & 20,0 & 66,0 & 9,6 & 0,0 & 0,10 & 1,4 & О.М.П. \\
\hline 551 & 2,2 & 0,0 & 0,0 & 0,0 & 0,4 & 2,0 & 87,6 & 8,8 & 0,8 & 0,0 & 0,17 & 1,2 & М.П. \\
\hline 552 & 1,0 & 0,0 & 0,0 & 0,0 & 0,6 & 36,5 & 57,5 & 5,5 & 0,2 & 0,0 & 0,21 & 1,4 & М.П. \\
\hline $553 \mathrm{~A}$ & 1,0 & 0,0 & 0,0 & 0,0 & 0,5 & 22,5 & 53,5 & 23,3 & 0,2 & 0,0 & 0,17 & 1,4 & М.П. \\
\hline 553 & 2,3 & 0,0 & 0,0 & 0,0 & 1,4 & 39,4 & 57,3 & 1,4 & 0,0 & 0,0 & 0,22 & 1,4 & М.П. \\
\hline 562 & 0,9 & 0,0 & 0,0 & 0,0 & 0,2 & 51,4 & 48,0 & 0,2 & 0,0 & 0,0 & 0,26 & 1,4 & С.П. \\
\hline 563 & 0,7 & 0,0 & 0,0 & 0,0 & 0,2 & 34,5 & 64,1 & 0,6 & 0,0 & 0,0 & 0,21 & 1,4 & М.П. \\
\hline 564 & 0,9 & 0,0 & 0,0 & 0,0 & 1,8 & 52,4 & 38,2 & 7,0 & 0,3 & 0,0 & 0,27 & 1,5 & С.П. \\
\hline 565 & 2,4 & 0,0 & 0,0 & 0,0 & 0,8 & 1,5 & 3,5 & 61,5 & 32,0 & 0,7 & 0,076 & 1,3 & П.Ал. \\
\hline 574 & 3,8 & 0,0 & 0,0 & 0,0 & 0,8 & 2,5 & 9,5 & 80,0 & 7,0 & 0,2 & 0,09 & 1,2 & О.М.П. \\
\hline 575 & 3,8 & 0,0 & 0,0 & \begin{tabular}{|l|}
0,0 \\
\end{tabular} & 1,1 & 15,5 & 49,5 & 23,5 & 10,2 & 0,2 & 0,14 & 1,5 & М.П. \\
\hline 576 & 3,5 & 0,0 & 0,0 & 0,0 & 1,1 & 13,0 & 52,5 & 24,5 & 8,2 & 0,2 & 0,15 & 1,5 & М.П. \\
\hline 583 & 3,2 & 0,0 & 0,0 & 0,0 & 0,0 & 2,5 & 12,5 & 45,5 & 37,4 & 2,1 & 0,07 & 1,4 & П.Ал. \\
\hline 584 & 1,1 & 0,0 & 0,0 & 0,0 & 0,6 & 2,3 & 73,5 & 22,8 & 0,6 & 0,0 & 0,16 & 1,3 & М.П. \\
\hline
\end{tabular}

Примечание. * К.П. - крупный песок; С.П. - средний песок; М.П. - мелкий песок; О.М.П. очень мелкий песок; П.Ал - песок алевритовый. 


\section{Заключение}

В результате изучения донных песчаных отложений было выявлено, что они распространены вдоль северного и южного побережий в виде непрерывной узкой (1,5-2,0 км) полосы от уреза до глубины 2,5-3,0 м. Значительное расширение (до 2,5-3,0 км) этой полосы наблюдается у южного побережья напротив устья р. Прохладной, что, повидимому, генетически связано с зандровыми полями прилегающей суши. На поверхности песчаных отложений повсеместно развита окисленная пленка, свидетельствующая о хорошем перемешивании придонного слоя воды, обитает моллюск Rangia cuneata. Наибольшее развитие имеют средние $(0,5-$ 0,250 мм) и мелкие $(0,250-0,125$ мм) пески, которые хорошо отмыты и отличаются очень хорошей сортированностью (So колеблется в пределах 1,2-1,8).

В гранулометрическом составе донных осадков обнаруживается характерная для подобных водоемов закономерность: песчаный материал с незначительным содержанием более тонких частиц сосредоточен в прибрежной зоне. Основные закономерности распределения фракций песчаного материала объясняются гидродинамической активностью водных масс, конфигурацией берегов и составом осадочного материала основных источников питания. Проведенные исследования касались верхнего (0-7 см) слоя осадков, для оценки мощности песчаных отложений и определения их вертикального строения потребуются дополнительные исследования.

Экспедиционные исследования и гранулометрический анализ проб донных осадков выполнялись при поддержке гранта РФФИ p a № 19-45-390013, анализ и интерпретациия данных выполнялись в рамках госзадания ИО РАН (тема № 0149-2019-0013).

\section{Список литературы / References}

1. Чечко В.А., Чубаренко Б.В., Топчая В.Ю. Влияние природных и антропогенных факторов на формирование осадочной толщи Калининградского залива Балтийского моря // Известия КГТУ. 2018. № 48. С. 47-58.

Chechko V.A., Chubarenko B.V., Topchaya V.Yu. Influence of natural and anthropogenic factors on the formation of sedimentary strata of the Kaliningrad Gulf of the Baltic Sea // Izvestiya KGTU. 2018. № 48. P. 47-58 (in Russian).

2. Лисицын А.П. Аридная седиментация в Мировом океане. Рассеянное осадочное вещество атмосферы // Геология и геофизика. 2011. Т. 52. № 10. С. 1398-1466.

Lisitsyn A.P. Arid sedimentation in the oceans and atmospheric particulate matter// Russian Geology and Geophysics. 2011. V. 52. № 10. P. 1100-1133. DOI: 10.1016/j. rgg.2011.09.006.

3. Лисицын А.П. Современные представления об осадкообразовании в океанах и морях. Океаны как природный самописец взаимодействия геосфер Земли // Мировой океан. T. 2. Физика, химия и биология океана. Осадкообразование в океане и взаимодействие геосфер Земли / Под общ. ред. Л.И. Лобковского и Р.И. Нигматулина. М.: Научный мир, 2014. С. $331-571$

Lisitsyn A.P. Modern ideas about sedimentation in oceans and seas. Oceans as a natural recorder of interaction of geospheres of the Earth // Mirovoy okean. T. 2. Fizika, khimiya i biologiya okeana. Osadkoobrazovaniye v okeane i vzaimodeystviye geosfer Zemli / Pod obshchey redaktsiyey L.I. Lobkovskogo i R.I. Nigmatulina. M.: Nauchnyy mir, 2014. P. 331-571 (in Russian).

4. Windom H.L., Schropp S.J., Galder F.D., Ryan J.D., Smith R.G., Burney L.C., Lewis F.G., Rawlinson C.H. Natural trace metal concentrations in estuarine and coastal marine sediments of the southeastern United States. Environmental Sciences and Technology. 1989. V. 23. № 3. P. 314-320. DOI: 10.1021/ es00180a008.

5. Фёдоров Ю.А, Гарькуша Д.Н., Тамбиева Н.С., Андреев Ю.А., Михайленко О.А. Влияние гранулометрического состава донных отложений озера Байкал на распределение метана и сульфидной серы // Литология и полезные ископаемые. 2018. № 4S. C. 1-13. DOI: 10.1134/S0024497X19010026.

Fedorov Yu.A., Garkusha D.N., Tambieva N.S., Andreev Yu.A., Mikhaylenko O.A. Influence of granulometric composition of bottom sediments of lake Baikal on methane and sulfide sulfur distribution // Litologiya i poleznye iskopaemye. 2018. № 4S. P. 1-13 (in Russian).

6. Кравчишина М.Д. Взвешенное вещество Белого моря и его гранулометрический состав. М.: Наука, 2009. 264 с.

Kravchishina M.D. Suspended matter of the White Sea and its particle size distribution. M.: Nauka, 2009. 264 p. (in Russian).

7. Буданова Т.Е., Озмидов О.Р., Озмидов И.О. Современные методы изучения гранулометрического состава грунтов // Инженерные изыскания. 2013. № 8. С. 66-71.

Budanova T.E., Ozmidov O.R., Ozmidov I.O. Modern methods for studying the particle size distribution of soils // Inzhenernye izyskaniya. 2013. № 8. P. 66-71 (in Russian).

8. Wentworth C.K. A scale of grade and class terms for clastic sediments. Journal of Geology. 1922. V. 30. № 5. P. 377-392.

9. Фролов В.Т. Литология. Кн. 2: Учеб. пособие. М.: Изд. МГУ, 1993. 432 с.

Frolov V.T. Lithology. Book 2: Uchebnoe posobie. M.: Izd. MGU, 1993. 432 p. (in Russian).

10. Kocheshkova O., Ezhova E., Dorokhov D., Dorokhova E. Benthic communities and habitats in the near shore zone of the Curonian Spit (the south-eastern part of the Baltic Sea). Baltica. 2014. V. 27. P. 45-54.

11. Chechko V.A., Blazchishin A.I. Bottom deposits of the Vistula Lagoon of the Baltic Sea. Baltica. 2002. Vol. 15. P. 13-22.

12. Чечко В.А. Особенности современных процессов осадкообразования в Вислинском и Куршском заливах // Система Балтийского моря / Ред. А.П. Лисицын. М.: Научный мир, 2017. С. 373-380.

Chechko V.A. Features of modern sedimentation processes in the Vistula and Curonian lagoons // Baltic Sea System / Red. A.P. Lisitsyn. M.: Nauchnyj mir, 2017. P. 373-380 (in Russian).

13. Chubarenko B., Chechko V., Pilipchuk V., Bulycheva E., Kileso A., Topchaya V. Hydrological and sedimentation conditions in non-tidal lagoon during ice-coverage - the example of the Vistula Lagoon, the Baltic Sea. Abstract book of 7th EUROLAG Symposium, 1-4 March 2016, Murcia (Spain). Compobell, Murcia, 2016. P. 52-53.

14. Рудинская Л.В., Гусев А.А. Вселение североамериканского двустворчатого моллюска Rangia cuneata в Вислинский залив Балтийского моря // Российский журнал биологических инвазий. 2012. № 2. С. 115-128.

Rudinskaya L.V., Gusev A.A. Introduction of the North American bivalve mollusk Rangia cuneata into the Vistula Lagoon of the Baltic sea// Rossijskij zhurnal biologicheskih invazij. 2012. № 2. P. 115-127 (in Russian). 